\title{
Human Papillomavirus-16 Negative
}

National Cancer Institute

\section{Source}

National Cancer Institute. Human Papillomavirus-16 Negative. NCI Thesaurus. Code C146716.

An indication that human papillomavirus-16 has not been detected in a sample. 